\title{
POÉTICA, ESTÉTICA Y CRÍTICA
}

\section{Amparo Zacarés \\ (Universidad Jaume I, Castellón)}

RESUMEN: En esta Nota biobibliográfica se narra el proceso de acercamiento de la Autora al pensamiento de Vico y de vinculación al estudio de la Estética, ciencia de la que hay que considerar a Vico su primer descubridor. Palabras ClaVE: Vico, $350^{\circ}$ Aniversario, estética, poética, crítica, Modernidad-Postmodernidad, humanidades, R. de la Calle, Cuadernos sobre Vico, A. Zacarés.

\section{Poetical, esthetical and critical}

ABSTRACT: This bio-bibliographical note narrates the Author's approach to Vico's thought the way she was introduced into the study of Aesthetics, a science of which Vico must be considered as his first discoverer.

KeYwords: Vico, $350^{\text {th }}$ Anniversary, aesthetics, poetry, criticism, Modernity-Postmodernity, humanities, R. de la Calle, Cuadernos sobre Vico, A. Zacarés.

\section{Poetica, estetica e critica}

RiASSUNTO: In questa Nota biobibliografica l'Autrice racconta come si sia avvicinata al pensiero di Vico e il suo legame con lo studio dell'Estetica, scienza di cui Vico è da considerare come il suo primo scopritore.

PARole ChiAve: Vico, $350^{\circ}$ Anniversario, estetica, poetica, critica, Modernità-Postmodernità, studi umanistici, R. de la Calle, Cuadernos sobre Vico, A. Zacarés.

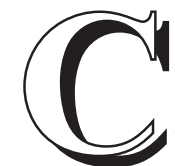

uando en los años Setenta del siglo pasado comecé mis estudios de filosofía, aún no sabía que iba a dedicar gran parte de mis intereses académicos a la investigación de la Scienza nuova ni que, pasado el tiempo, llegaría a formar parte de un círculo de estudiosos viquianos repartidos por el mundo. En una época en la que en las aulas universitarias de la Universitat de València (UV) se impartía estructuralismo, fenomenología, semiótica, filosofía del lenguaje y lógica matemática, no había un lugar definido para el área de Estética y Teoría de la Artes, ni tampoco 
existía un Departamento de Estética en la misma Facultad de Filosofía y Ciencias de la Educación. Por este motivo mis primeras palabras han de ser de agradecimiento para el profesor Román de la Calle, ${ }^{1}$ que impulsó la creación del Instituto Universitario de Creatividad \& Estética así como el Departamento de Estética en el distrito universitario de Valencia. Sin sus enseñanzas y sin su dirección no hubiera llegado a Vico como el filósofo que, según había señalado Croce, ${ }^{2}$ podía considerarse el primer descubridor de la ciencia estética. Como se sabe, Vico no escribió ningún texto específico sobre tal disciplina, ni utilizó el término estética que más tarde crearía Baumgarten, sin embargo en la gnoseología de la Scienza nuova, al igual que en la obra del propio Baumgarten; se daban dos partes, una estética que se ocupaba del saber sensible y otra lógica que trataba del saber intelectual. En ese sentido, puede decirse que el horizonte teórico de la estética moderna aparece ya en la obra de Vico antes que en la de Kant, de tal modo que en los tratados de estética se simultanean ambos filósofos a la hora de reconocer la especificidad de una nueva disciplina filosófica que trataba de la experiencia de la belleza y de las producciones artísticas.

Dicho esto, quisiera matizar que, al escribir esta nota bio-bibliográfica, siento que mi relato incluye no solo parte de mi vida académica sino también la valoración profesional de un ámbito de reflexión y de una disciplina, la estética, que en aquel entonces pasaba por ser la hermana menor de la filosofía. De ahí que empareje lo subjetivo con lo objetivo pero, al mismo tiempo, intente trascender la mera subjetividad. Después de todo, hablar de Vico desde un planteamiento autobiográfico propio exige poner palabras al esfuerzo realizado en estos años que, en mi caso, incluyen tanto conversaciones amistosas como discrepancias intelectuales. En esa línea argumentativa, mi primer recuerdo se centra en mi memoria de licenciatura (1982), que tuvo como objetivo demostrar que en Vico se hallaban ya los antecedentes de la semiótica. Luego, a medida que preparaba mi tesis doctoral y me adentraba más en el pensamiento viquiano, surgieron cuestiones propias de la estética, relativas al gusto y a la belleza y relacionadas con saber si existen o no patrones universales para el criterio del gusto. Así, la tesis que defendí en 1988 se tituló La poética de G.B. Vico: Historia y Actualidad ${ }^{3}$, y recogía aquellos aspectos del pensamiento de Vico que habían despertado el interés de la hemenéutica y de la teoría literaria. Me decanté por analizar cómo la historia y la crítica literaria moderna de las primeras décadas del siglo XIX, eran deudoras de la influencia de Vico. Por una parte, la historia literaria acogió la filología como disciplina de ayuda en la recons-

1. HuerTa, R., Romà de la Calle: l'impuls estètic en art i educació, Ed. Universitat Politècnica de València, Valencia, 2012.

2. Croce, B., La filosofia di G.B. Vico, Laterza, Bari, 1965.

3. Zacarés, A., La poètica de G.B. Vico: Historia y actualidad, Servicio de Publicaciones de la Universitat de València, Valencia, 1988. 
trucción de los textos literarios del pasado y, por otra, la crítica se interesó por la poesía y la creación literaria en general. Es cierto que Vico hizo recaer su atención en una filosofía de la historia más que en una interpretación de los textos literarios, pero lo importante era que las manifestaciones artísticas constituían un punto crucial en su obra y que entendía el arte como una manifestación innata y connatural del ser humano, hasta el punto de que el estudio del desarrollo histórico de nuestra humanitas había de pasar necesariamente por la investigación de las producciones artísticas colectivas. Así, aunque se dijera que su interés no era estético sino histórico, el hecho de que hiciera recaer la importancia de la poesía no solo en el lenguaje sino también en las instituciones de los pueblos primitivos, fue determinante para mis estudios de estética. Esa visión histórica de la humanidad, que podía entenderse como el paso del Renacimiento al historicismo de los tiempos modernos y que, según Fubini, ${ }^{4}$ representó una revolución comparable a la copernicana, fue mi punto de arranque para investigaciones posteriores.

Pero en aquellos años me dediqué a rastrear sobre todo el interés que la obra de Vico despertó en la "nouvelle critique", comprobando que la poética de Genette desembocaba en una historia estructural de la literatura y de la psicología colectiva en el estudio del hecho literario. Genette se acercaba a la retórica viquiana en tanto que establecía un análisis filológico-antropológico cuya idea estructuradora era la de seguir la evolución de la humanidad, practicando cortes sincrónicos en diversas etapas. Por su parte, Todorov también seguía la línea iniciada por Vico al proponer un programa de poética estructural donde la poética y la historia literaria colaborasen mutuamente, y apuntaba la posibilidad de una gramática universal del relato que decía basarse en una realidad psicológica común. La inclusión de Vico en los estudios de la teoría literaria moderna, en las nuevas poéticas y en las corrientes filosóficas que predominaban a finales del siglo XX, tuvo su origen en la crítica a la historia estructural y puso de manifiesto los riesgos de la sobrevaloración del método sincrónico, que olvidaba la dimensión histórica de las manifestaciones literarias. Para llegar a esta conclusión, los estudios de Andrea Battistini ${ }^{5}$ me fueron de gran ayuda. Gracias a sus estudios se hizo evidente que la "nouvelle critique" había extraído algunas enseñanzas de la teoría estética y de la retórica viquiana, especialmente después de la publicación en la revista Te Quel de la carta que Vico dirigió a su amigo Gherardo degli Angioli en 1725, donde exponía sus consideraciones críticas sobre la índole de la auténtica poesía y sobre el genio poético de Dante al que consideraba como «Homero retornado». Hasta el punto de que aquel cantor ciego y errante que fue Homero se convierte en el referente de la grandiosidad poética de la Antigüedad, pues para Vico la sublimidad del poeta reside en la fuerza de su inven-

4. Fubini, M., Critica e Poesia, Laterza, Bari, 1956; ID., Stile e umanità de G.B. Vico, Ricciardi, Milán, 1965.

5. Battistini, A., La Degnità della Retorica, Pacini, Pisa, 1975. 
tiva y no en el sometimiento a unos cánones establecidos o reglas impuestas, como hizo el neoclasicismo francés que, en el debate conocido como la querelle entre antiguos y modernos, enfrentó a detractores y adeptos de Homero.

También entonces me interesaban las cuestiones relativas al problema de la unidad del saber y el divorcio de las dos culturas, la científica y la literaria, de la que había hablado Snow en 1959. En definitiva, en esa línea argumentativa inicié mis investigaciones sobre Vico, que cristalizaron en la tesis doctoral citada y que fue dirigida por el profesor Román de la Calle. A resultas de esto, me cabe el orgullo y la satisfacción de haber presentado, el 16 de abril de 1988, la primera tesis sobre Vico que se defendió en la Universidad de Valencia (UV). Fueron años en los que impartí seminarios universitarios sobre la poética y la teoría estética de Vico, ampliando de este modo la perspectiva de los estudiantes universitarios que en los cursos reglados de estética tomaban contacto sobre todo con los textos de Kant y Hegel. En las aulas se explicaba también el idealismo de Croce, el marxismo de Lukàcs y Della Volpe, la estética de Dufrenne y Hartmann, pero apenas se citaba a Vico. De ahí que aquellos seminarios de extensión universitaria que, durante más de una década, impartí en la sede del Instituto de Creativitat \& Estética de la Facultad de Filosofia contribuyeron a difundir la teoría poética de Vico, ayudando a descubrirla y considerarla en su justo reconocimiento dentro de la historia de la estética.

Siguiendo con el relato bio-bibliográfico, no podía faltar mi agradecimiento al profesor José Manuel Sevilla, alma mater del círculo viquiano en España al crear el "Centro de Investigaciones sobre Vico" (CIV) e impulsar la revista universitaria Cuadernos sobre Vico (CSV), cuyo primer número se editó en 1991. En la actualidad el boletín de estudios viquianos de la Universidad de Sevilla se ha convertido en una de las publicaciones de renombre internacional para el entorno de los estudiosos de Vico. Una iniciativa que aglutina una corriente de pensamiento ligado al humanismo viquiano en sus diversas facetas y que, sin duda, ha contribuido a situar en el debate filosófico cuestiones políticas, epistemológicas, éticas y estéticas de nuestra época. Por este motivo, nunca estará de más recordar el punto de inflexión que los profesores José Manuel Sevilla y Miguel Antonio Pastor han supuesto para la investigación y la difusión universitaria de los estudios sobre Vico. A ellos se debe el mérito de que CSV saliera a flote ininterrumpidamente durante más de veinticinco años y que aún hoy, sorteando épocas de recortes económicos, se siga publicando. A mi entender, no es una exageración decir que $C S V$ contiene ya uno de los legados intelectuales de mayor calado en la filosofía y en la historia de las ideas desde finales del siglo XX hasta nuestro días. Por todo ello no puedo dejar de reconocerles mi gratitud, ya que para mí ha sido un honor saberme partícipe de este proyecto desde sus inicios.

En CSV publiqué varios artículos, el primero en el número inicial de 1991 y el último en 2017. Si se leen puede verse cómo, sobre la base de las ideas viquia- 
nas, he ido avanzando e interesándome por cuestiones relativas a la clasificación de los sistemas de saber y a la crítica al positivismo y al cientificismo de nuestra época. Pero de esta década subrayaría la publicación en 1998 de mi libro Filosofía y poesía: El logos recobrado ${ }^{6}$ a cargo de la Institució Alfons el Magnànim de la Diputación de Valencia. Se trata de un excursus filosófico para la reconstrucción de la confianza en la sabiduría poética, donde explico cómo el lógos doxátos de los sentidos no es en Vico un lógos falso y, siguiendo las ideas de Rella, ${ }^{7}$ defiendo la imposibilidad de repetir el gesto platónico-cartesiano que creía llegar a una verdad absoluta, ignorando las apariencias de lo múltiple, condenando todo discurso que no fuera reflexivo por engañoso o ficticio. En la modernidad los términos de la batalla por la verdad no podían ser como antaño. Tal contienda ya no estaba entre una verdad invisible que se trasmite a través de un lenguaje privilegiado, el filosófico, y la experiencia variada de lo visible, que se comunica a través de un discurso narrativo o poético. En suma, cuando la verdad dejó de guardar relación con el Bien y se situó en el terreno de la sabiduría leopardiana, en el saber de la vida, la confianza en la razón poética no podía dejar de lado a Vico y este había de ocupar por derecho propio un lugar importante en la comprensión de la historia del pensamiento y de la filosofía. A tenor de estas consideraciones, la casualidad ha hecho que, en estos momentos en los que escribo esta nota bio-bibliográfica, me encuentre sumida en un proyecto filosófico relacionado con María Zambrano y su reivindicación como la filósofa de la Generación del '27. Se trata de un proyecto compartido con la artista Rosa Mascarell, que atendió como secretaria a la filósofa a su vuelta a España después de tantos años de exilio. La cercanía entre Zambrano y Vico resulta evidente, también ella establece las bases de un pensamiento icónico originario, de un pensar poético en imágenes, donde el transitar por el tiempo no es un ir y venir discurriendo, sino un mirar de forma circular, donde la primacía está en el sentir de un sujeto que se percibe sintiendo. De este modo, enfrentando poema a sistema, la filósofa afirma que pensar es antes que nada descifrar lo que se siente. Por ello, si bien Vico fue quien equiparó la poesía con la primera categoría mental y expresiva de nuestra filogénesis, María Zambrano no le fue a la zaga al afirmar que el primer lógos tuvo que ser delirio y que, en ese sentido, Homero es digno de admiración y veneración. ${ }^{8}$

Por otra parte, volviendo a la década de los Noventa del siglo pasado, quisiera referirme al Congreso Internacional Pensar para el Nuevo Siglo, dedicado a Vico y la cultura europea, que tuvo lugar en Sevilla, en 1999, y que fue organizado por el profesor José M. Sevilla y sus colaboradores del CIV. Fue una ocasión para presentar la multidisciplinaridad con la que en ese momento se abordaban los estu-

6. ZaCARÉs, A., Filosofía y poesía: el logos recobrado, Ed. Institució Alfons el Magnànim (Diputaciò de València), Valencia, 1998.

7. Rella F., La battaglia della verità, Einaudi, Turín, 1986.

8. Zambrano, M., Filosofia y poesia, F.C.E., México, 2006. 
dios viquianos y dejó, en quienes participamos en aquel foro, el grato recuerdo de hacer más oportuna que nunca su relectura. Presenté entonces una comunicación dedicada a demostrar que Vico logró el primer tour d'horizon, el primer examen general de la situación de los procesos de investigación y sistemas de conocimiento de la cultura europea de su época. En mi opinión, la Scienza nuova es la referencia en el pasado del actual debate sobre el estatus teórico de los sistemas de saber de nuestra cultura. Si hoy el discurso de la modernidad, mirando hacia atrás, fija la atención en Vico más que en Comte, no es porque la Scienza nuova sea un antídoto contra las consecuencias tardías del Cours de philosophie positive, sino porque el pensamiento del filósofo napolitano es hoy un aliado natural en defensa de la filosofía. Una cuestión en nada menor, habida cuenta del ocaso que hoy sufren los estudios humanísticos y del panorama tan desolador que padecen las humanidades. Por eso no resulta baladí recalcar que entre la ciencia nueva de la que habló Vico, con la que se daba relieve a las producciones artísticas humanas, y las ciencias del espíritu que presentó Dilthey, existe una continuidad evidente. En ambos casos se está al acecho para evitar el reduccionismo de una razón pura que es insuficiente para comprendernos como personas. Pero de lo que no me cabe duda es de que, en la actualidad, cuando lo humano ha quedado reducido a categorías económicas y es sutilmente sometido y manejado por lo que se conoce ya como "Cuarta Revolución Industrial", resulta más urgente que nunca encontrar un lugar para un tipo de saber que nos recuerde la dimensión corporal, trágica y trascendente de nuestra existencia.

Ya en los inicios del nuevo siglo, tuve la oportunidad de entrar en contacto con la Facultad de Bellas Artes de la Universidad Politécnica de Valencia (UPV), donde desde el Departamento de Escultura se dirigían tesis de reflexión estética muy vinculadas a las formas de conocimiento llamadas corporales. En especial las que dirigían el profesor Miguel Molina y la profesora Marina Pastor, que también tuvieron como maestro a Román de la Calle. De esa conexión surge mi inmersión en las llamadas poéticas participativas de las últimas décadas del milenio y pude descubrir la similitud que guardaban con las ideas de Vico. En esa línea de investigación participé en el Seminario de Cultura Visual, Historia del Arte, Imagen y Patrimonio Artístico, organizado en el Consejo Superior de Investigaciones Científicas (CSIC). En aquella ocasión, en la sesión celebrada en su sede de Madrid, el 16 de diciembre de 2011, presenté mis notas sobre la poética viquiana y su conexión con el arte participativo contemporáneo, que más tarde se convirtieron en el artículo que se publicó en $C S V$ en 2017. ${ }^{9}$ En aquel texto reflejé cómo hoy, en una época del fin del arte y de las bellas artes, de las instalaciones y del arte conceptual, la relevancia de Vico en el ámbito de la estética, reside en habernos ayudado a revi-

9. ZACARÉS, A., «La poética viquiana y su conexión con el arte participativo contemporáneo», Cuadernos sobre Vico, n. 30-31 especial XXV Aniversario, 2016-2017. 
sar una de las cuestiones más candentes, como es la de entender qué están haciendo los artistas en la actualidad. Es en este sentido en el que su estética de la sensibilidad puede arrojar algo de luz y aclarar por qué los artistas han desplazado sus intereses hacia el ámbito de la verdad más que hacia el de la belleza. Es más, su estética del cuerpo, con las limitaciones pertinentes, puede servir de ayuda para comprender que las propuestas creativas del arte de acción son una apuesta para replantearnos nuestra evolución y nuestra naturaleza histórica en estos tiempos de post-humanidad y cyborgs.

De hecho el tópos sensorial en el que se encuentran los espectadores y el artista en las poéticas participativas del arte de acción, guarda relación con una concepción de la verdad como poíesis, invención o creación. Es en ese sujeto receptor, en ese sujeto afectado sensorialmente e impelido a nivel psíquico a interpretar lo que está ocurriendo en el momento, donde acontece la conexión con aquel primer tipo de espectadores del mundo que fueron nuestros más antiguos predecesores en la prehistoria de la humanidad. Vico trató a aquellos primeros moradores y fundadores de las naciones como si hubieran sido el primer público participativo que existió. Un público sometido por necesidad a una recepción interpretativa y no a una mera contemplación pasiva con ánimo de deleite visual o goce estético. Un proceso interpretativo de autocomprensión en el que, al igual que hoy, se involucraba al público/espectador y se reconocía la categoría antropológica de la poesía y de la creatividad dentro de los orígenes comunes de nuestra historia. En todo ello hay que detectar el legado de Vico en la historia reciente de las ideas estéticas. A mi entender, indagar qué es verdaderamente el arte es preguntarnos qué fuimos y en qué hemos transformado nuestra humanitas. Y no hay la menor duda de que, para este tipo de esclarecimiento, la ideas estéticas de Vico son esenciales. He de decir también que, en estas consideraciones, siempre he valorado y considerado las investigaciones de los profesores Ernesto Grassi y Giuseppe Patella. ${ }^{10}$

Para finalizar, me remitiré a estos últimos años y a mi labor de docente en la UV, señalando mi participación en el trabajo de investigación $\mathrm{I}+\mathrm{D}$ titulado Comportamientos artísticos de fin de siglo en el contexto valenciano. Precedentes de las poéticas de la globalización, coordinado por la profesora Carmen Senabre, con la colaboración del profesor Ricard Silvestre y del actual director del Consorci de Museus de la Comunitat Valenciana, José Luis Pérez Pont. Poco después, ya como docente de la Universitat Jaume I de Castelló (UJI), enseñé las ideas de Vico en las asignaturas de "Historia del Gusto" y "Estética y Modernidad", de la misma forma que en años anteriores lo había hecho en la UV en las asignaturas "Historia

10. Grassi, E., Arte como antiarte. Ensayo sobre la teoria de lo bello en el mundo antiguo, Anthropos, Barcelona, 2016. Patella, G., Senso, corpo, poesia . Giambattista Vico e l'origine dell'estetica moderna, Guerini, Milán, 1995; e ID., Articolazioni, Saggi di filosofia e teoria dell'arte, ETS, Pisa, 2010. 
de las ideas estéticas" y "Estética". En la actualidad formo parte del área de Estética y Teoría de las Artes, del Departamento de Historia, Geografía y Arte de la Facultad de Ciencias Humanas y Sociales. Mis compañeros, la profesora Rosalía Torrent y el profesor Juan Manuel Marín, comparten conmigo haber sido discípulos de Román de la Calle quien, el 21 de noviembre de 2017, en la celebración de la apertura del curso académico, fue investido doctor honoris causa por la UJI y cuya laudatio correspondió al vicerrector de cultura, el profesor Wenceslao Rambla, vinculado también al maestro.

Y como si se tratara de cerrar un círculo, después de las investigaciones sobre poética y de los años de docencia en estética, he llegado finalmente a la crítica de arte, donde también los conocimientos de Vico me han sido de gran ayuda. Los lineamientos de estética que aprendí en mi juventud y que desarrollé a lo largo de estudios posteriores ${ }^{11}$ dan cuenta de parte de mi dedicación actual. Así, en la actualidad, compagino docencia y crítica como miembro de la Associació Valenciana de Crítics d'Art (AVCA). En definitiva, poética, estética y crítica son términos que sirven para definir mi quehacer docente e investigador de más de tres décadas. Puede decirse que, en mi trayectoria académica, Vico ha dejado su huella y ha estado presente siempre. Fue un acierto que mi director de tesis, Román de la Calle, me pusiera sobre su pista y fue también crucial que el "Centro de Investigaciones sobre Vico" y la revista Cuadernos sobre Vico, gracias -como se ha dicho- al esfuerzo de los profesores José M. Sevilla y Miguel A. Pastor, mantuvieran vivas las ideas viquianas en el debate filosófico contemporáneo. Sé que lo he mencionado antes, pero de nuevo vaya mi gratitud hacia ellos y hacia todos quienes me han acompañado en este itinerario porque, a fin de cuentas, en este tramo del recorrido ya no podría entenderme ni vital ni profesionalmente sin las enseñanzas de Vico.

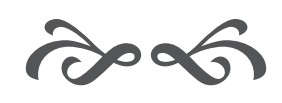

11. De La Calle, R., Estética \& Crítica, Ed. Edivart, Valencia, 1983; ID., A propósito de la crítica de arte. Teoría y práctica. Cultura y política, CI Creativitat i Ricerca, Valencia, 2012. 